\title{
INFORMATION AND COMMUNICATION TECHNOLOGIES IN PUBLIC MANAGEMENT OF THE HEALTHCARE INSTITUTIONS NETWORK DURING COVID-19 PANDEMICS
}

10.36740/WLek202011136

\author{
Dmytro A. Samofalov' ${ }^{1}$, Nataliya V. Izhytska ${ }^{2}$, Natalia M. Dragomyretska' ${ }^{1}$, Artem V. Lyashenko ${ }^{3}$ \\ 'ODESSA REGIONAL INSTITUTE FOR PUBLIC ADMINISTRATION OF THE NATIONAL ACADEMY FOR PUBLIC ADMINISTRATION UNDER THE PRESIDENT OF UKRAINE, \\ NATIONAL HEALTH SERVICE OF UKRAINE, ODESA, UKRAINE \\ ${ }^{2}$ DANYLO HALYTSKY LVIV NATIONAL MEDICAL UNIVERSITY, LVIV, UKRAINE \\ 3ODESSA REGIONAL CLINICAL HOSPITAL, ODESA, UKRAINE
}

\begin{abstract}
The aim was to study the structure, routes and algorithms of telemedical network in Odessa region and its impact on the spread of COVID-19 pandemics.

Materials and methods: We have analysed the data of the official reporting documentation provided by the Department of Healthcare of Odessa region. So the description of legislative acts and structure of telmedical network of 0dessa region is given. In more detail, we described functions and capabilities of telmedical network COVID-19 pandemics. Conclusions: Studies have shown that Telemedicine can be used in 5 main directions: Triage and decisions regarding hospitalization to hospitals designed for COVID-19 patients or to other hospitals. Outpatient consulting in COVID-19 patients who stay at home. Coordination of activities of different hospitals; provision of specialized consulting. Training of healthcare providers for counter-epidemic measures and management of COVID-19 patients. Routine consulting in patients with chronic disease and in palliative cases. In all this activities significant benefits were founded. But amount of telemedical consultations are quiet low.

As in all viral pandemies remote consultations of patients leeds to lowering in amount of infection of COVID-19 patients.
\end{abstract}

KEY WORDS: COVID-19, Triage, Telemedicine, Remote Consultation, Health Communication

Wiad Lek. 2020;73(11):2535-2542

\section{INTRODUCTION}

Humanity faces a new pandemic of SARS-CoV-2 infection which was declared as an international public health emergency by WHO. Fast and uncontrolled spread of COVID-19 infection poses a serious threat to the health of the entire population. The most recent pandemic of influenza A (H1N1) virus occurred in 2009. Just for first year it caused between 100000 and 400000 deaths globally. But it was not so massive as a current COVID-19 pandemics [1]. According to actual report of Kyiv school of economics on 1 of August it is already 17106007 infected and 668910 death in the world. The problem also concerns Ukraine and total score of infected and death are 71056 and 1709 $(2,4 \%)$ respectively $[2,3]$.

Healthcare systems of multiple countries turned to be totally unfit during the epidemics: healthcare providers were not only psychologically unready to face the unusual workload pressure but also unaware of crucial counter-epidemic actions; moreover, many of them were unable to use personal protection items [4].

Therefore, many healthcare professionals have fallen victims to COVID-19 infection themselves. The burden of COVID-19 among healthcare professionals at least from 23000 to 9000 are infected and hundreds have already died [5]. But governments do not collect the data accurately, so the total score is unknown. In Ukraine 8 745 healthcare professionals were infected and 43 died because of complications according to information from Ministry of Health. The well-being of the health care workforce is the cornerstone of every well-functioning health system $[6,7]$.

Many scientists report failure of old strategy of coordination of healthcare institutions and other contributors [8]. The new strategy should include changed approaches to diagnosing, treatment and development of drugs and vaccines. Actions that can overcome the epidemics include changes of communication activities targeting maximum isolation of infected persons and contacts as well as social distancing of healthy persons. Another significant contribution is coordination provided by administrative institutions. Many authors consider information and communication technologies a central element of counter-epidemics strategy $[9,11]$.

\section{THE AIM}

Description of structure, routes and algorithms of telemedical network in Odessa region as a central communication component of healthcare institutions management under the conditions of COVID-19 pandemics. 


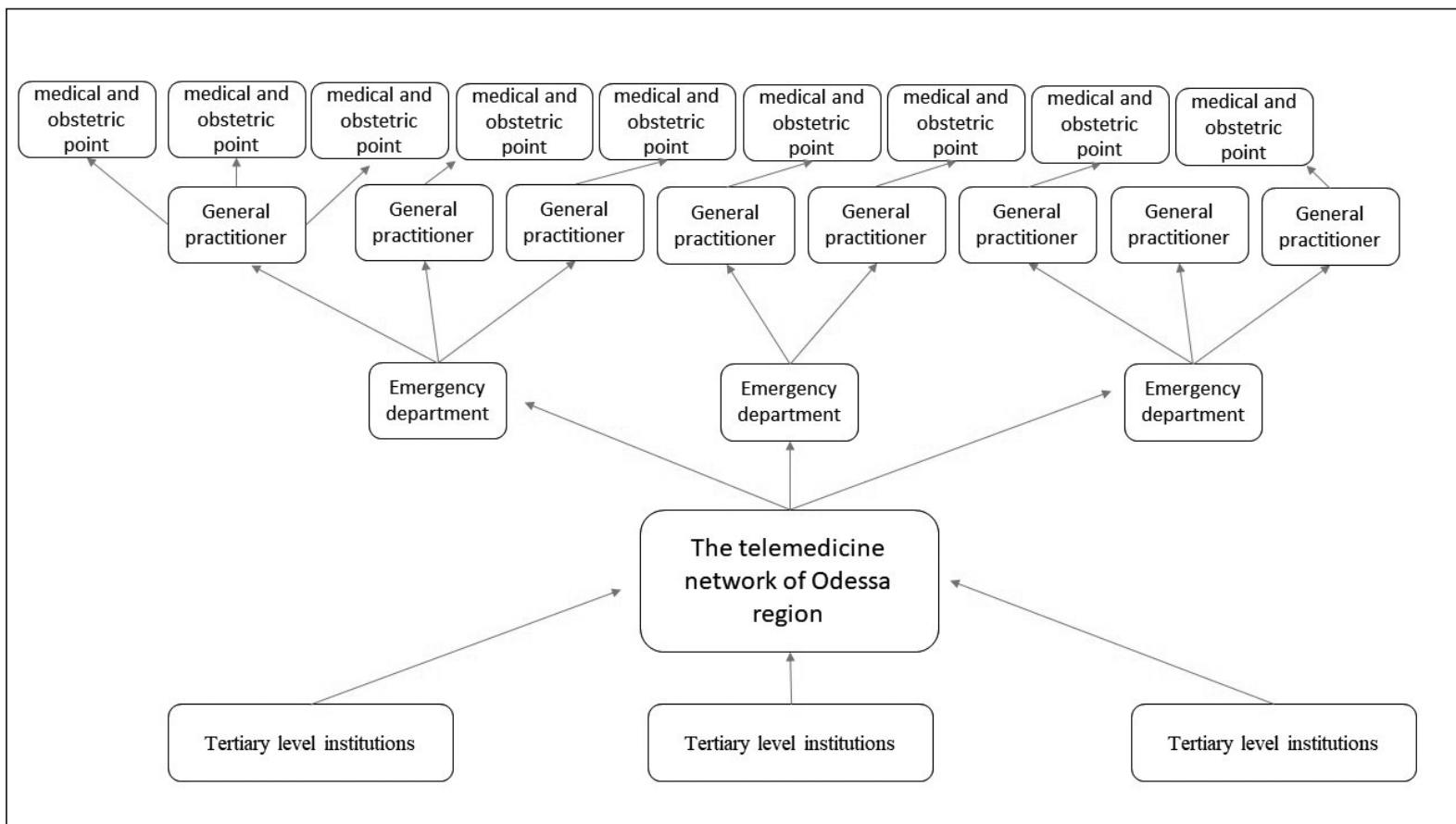

Fig. 1. The structure of the telemedicine network of Odessa region

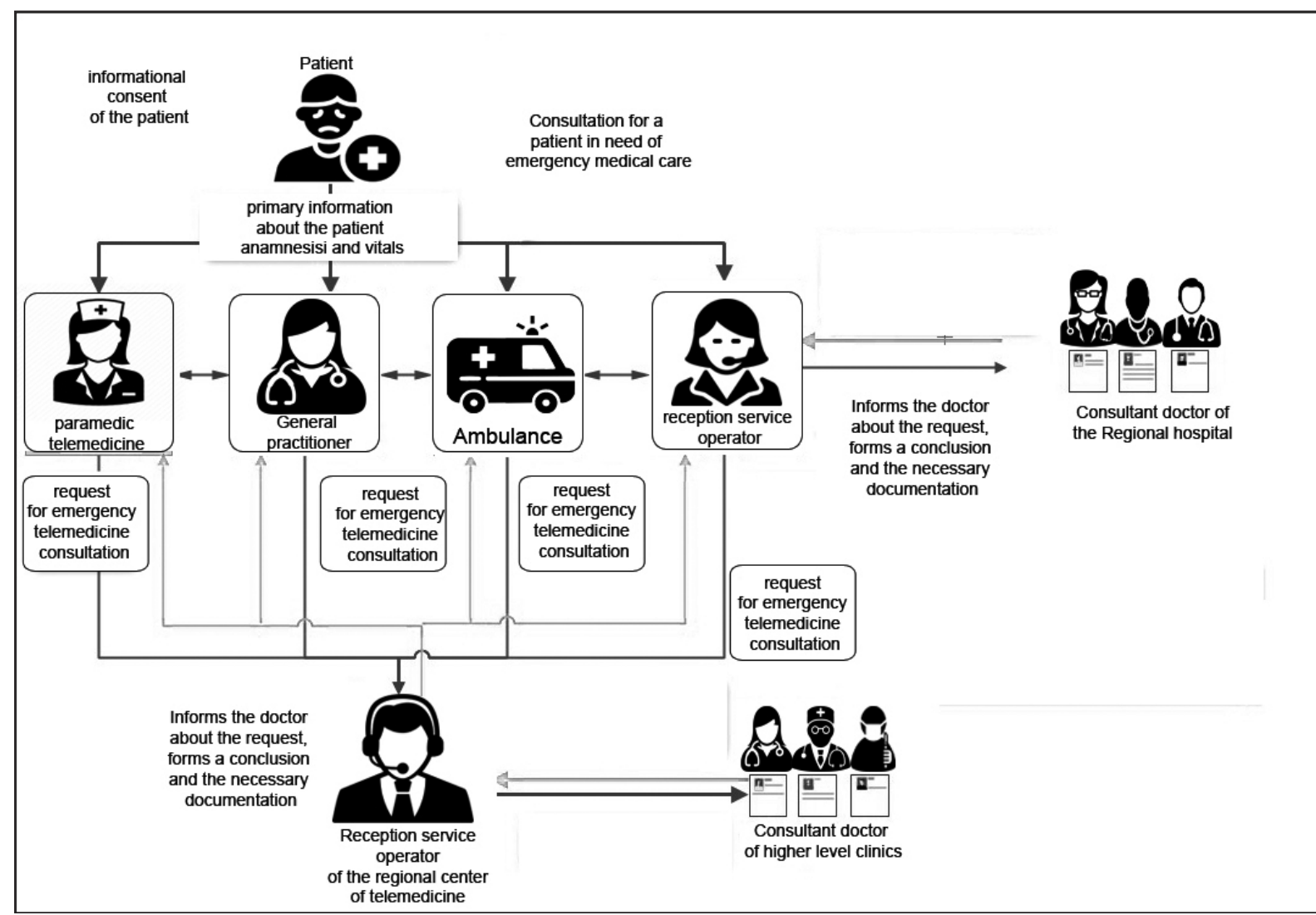

Fig. 2. Technological scheme of emergency telemedicine consultations of a patient with suspected coronavirus is designed to work for a limited period of time.

Review of healthcare institutions management practices under the conditions of COVID-19 pandemics including the use of information and communication technologies both in Odessa region and in developed countries. Analyze the telemedicine system coordination capacity in Odessa region in response to COVID-19 pandemics based on published data.

\section{MATERIALS AND METHODS}

This is a descriptive study providing empirical information 


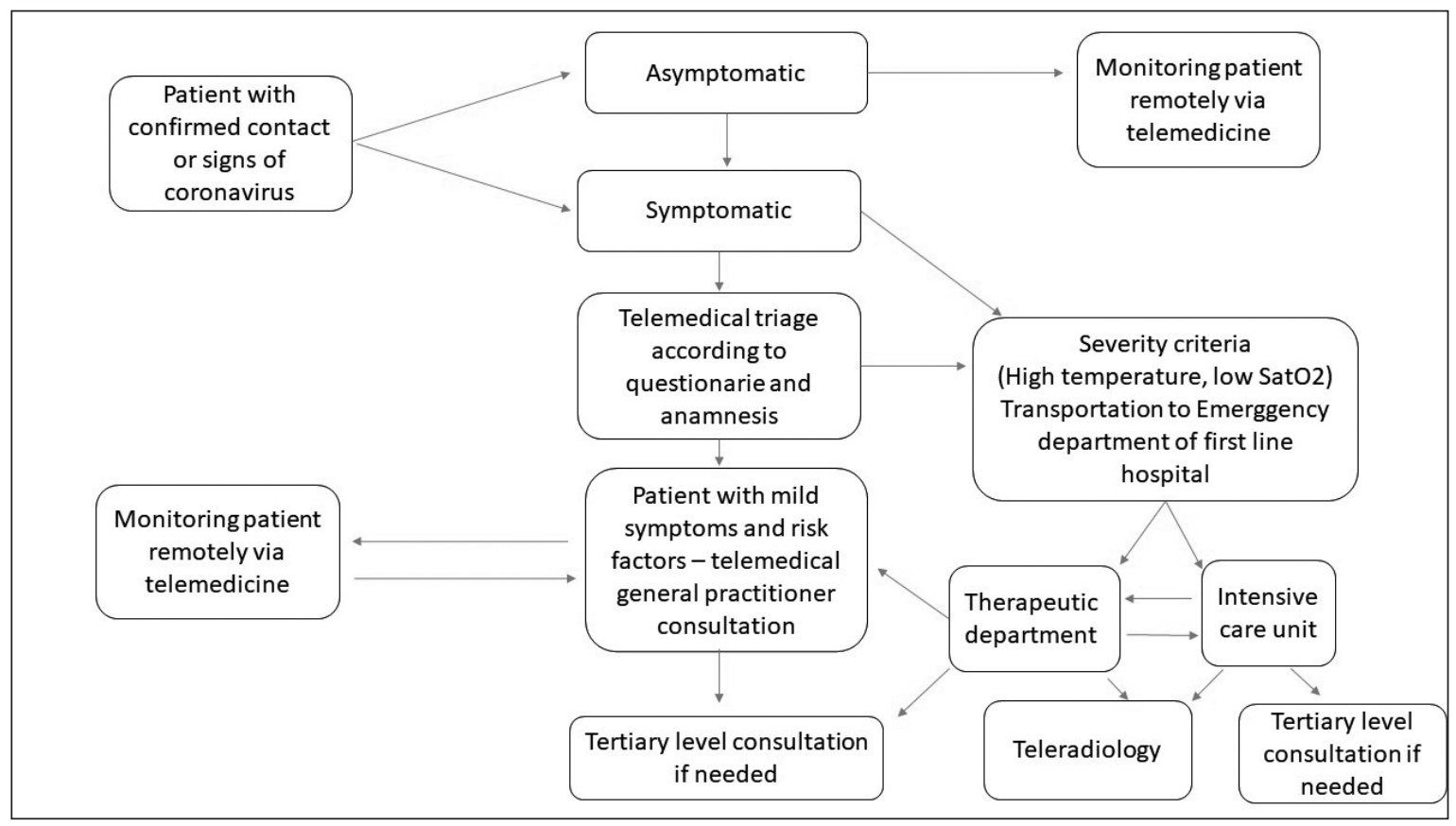

Fig. 3 Telemedical triage of patient with COVID-19

Table I. Distribution of patients with coronavirus according to age groups.

\begin{tabular}{cc}
\hline Age intervals & Patients $\mathbf{n}=\mathbf{6 5}$ \\
\hline $0-1$ years & 0 \\
\hline $1-14$ years & 0 \\
\hline $14-40$ years & 16 \\
\hline 40-60 years & 30 \\
\hline Above 60 years & 19
\end{tabular}

Table II. Detected contact with COVID-19 among the consulted patients.

\begin{tabular}{ccc}
\hline Risk factors & Patients $\mathbf{n}=\mathbf{6 5}$ & $\%$ \\
\hline $\begin{array}{c}\text { Detected contact with } \\
\text { COVID-19 }\end{array}$ & 10 & $15,38 \%$ \\
\hline $\begin{array}{c}\text { Trips abroad 14 days before } \\
\text { the first symptoms }\end{array}$ & 2 & $3,07 \%$ \\
\hline $\begin{array}{c}\text { No detected contact or trips } \\
\text { abroad 14 days before the first } \\
\text { symptoms }\end{array}$ & 53 & $81,53 \%$ \\
\hline
\end{tabular}

and descriptive statistics of public management system regarding the region-based pattern of COVID-19 patients hospitalization in healthcare institutions of Odessa region supported by telemedicine network (Telehealth system) with Odessa Regional Telemedicine Center as the leading element of patient's routes coordination.

The Odessa region telemedicine network has been developed in compliance with the following legislation acts: the Law of Ukraine "Fundamentals of the Legislation of Ukraine on Health Care", the Law of Ukraine "Improvement of medical care accessibility and quality in rural areas", the Law of Ukraine "Governmental financial guarantees of medical care", the Order of Ministry of Health
(MoH) of Ukraine dated 28.09.2012, №752 “Order of medical care quality control”, the Order of MoH of Ukraine dated 21.09.2012, № 732 "Approval of the Plan of MoH of Ukraine regarding the implementation of medical care quality management program in Ukraine until 2020", the Order of MoH of Ukraine dated 19.10.2015, № 681 “Approval of specifications for implementation of telemedicine in the field of healthcare", as well as the Orders of Odessa region Healthcare department "Organization of medical care based on telemedicine technologies in the Odessa region" and "Organization of urgent outpatient medical care based on telemedicine technologies in the Odessa region".

The telemedicine network of Odessa region (Figure 1) includes 89 healthcare institutions.

- 29 primary level medical care institutions;

- 37 secondary level institutions;

- 19 tertiary level institutions;

The network is subdivided in two tiers: 32 telemedicine offices in regional healthcare institutions are running the consulting projects; they are connected to 37 offices and 29 telemedicine checkpoints that are receiving the consulting info.

Regional center of telemedicine is the central coordination element of the system. It runs the management, organization and technical support and provides methodology framework for the system. The center includes the following elements:

- Operative reception service, 7 positions;

- Technical maintenance department, 5 positions;

- Information support department, 5 positions.

Moreover, 18 reception service operators are localized in the telemedicine offices at the regional hospitals, namely: the Regional hospital of Sarata, the Regional hospital of Kodyma, the Regional hospital of Podilsk, the Regional 


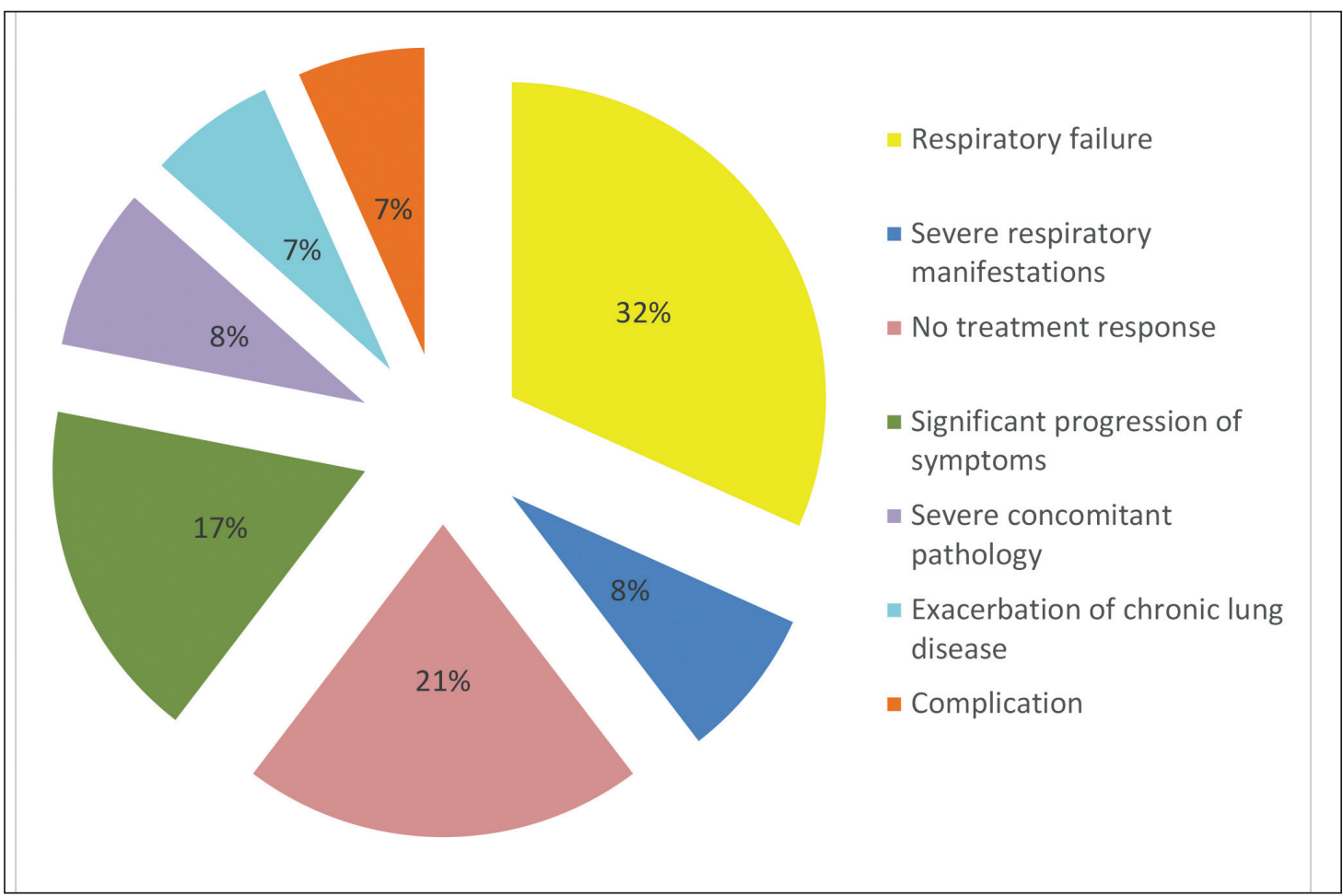

Fig. 4. Causes for hospitalization of patients with acute respiratory disease COVID-19, after telemedicine consultation.

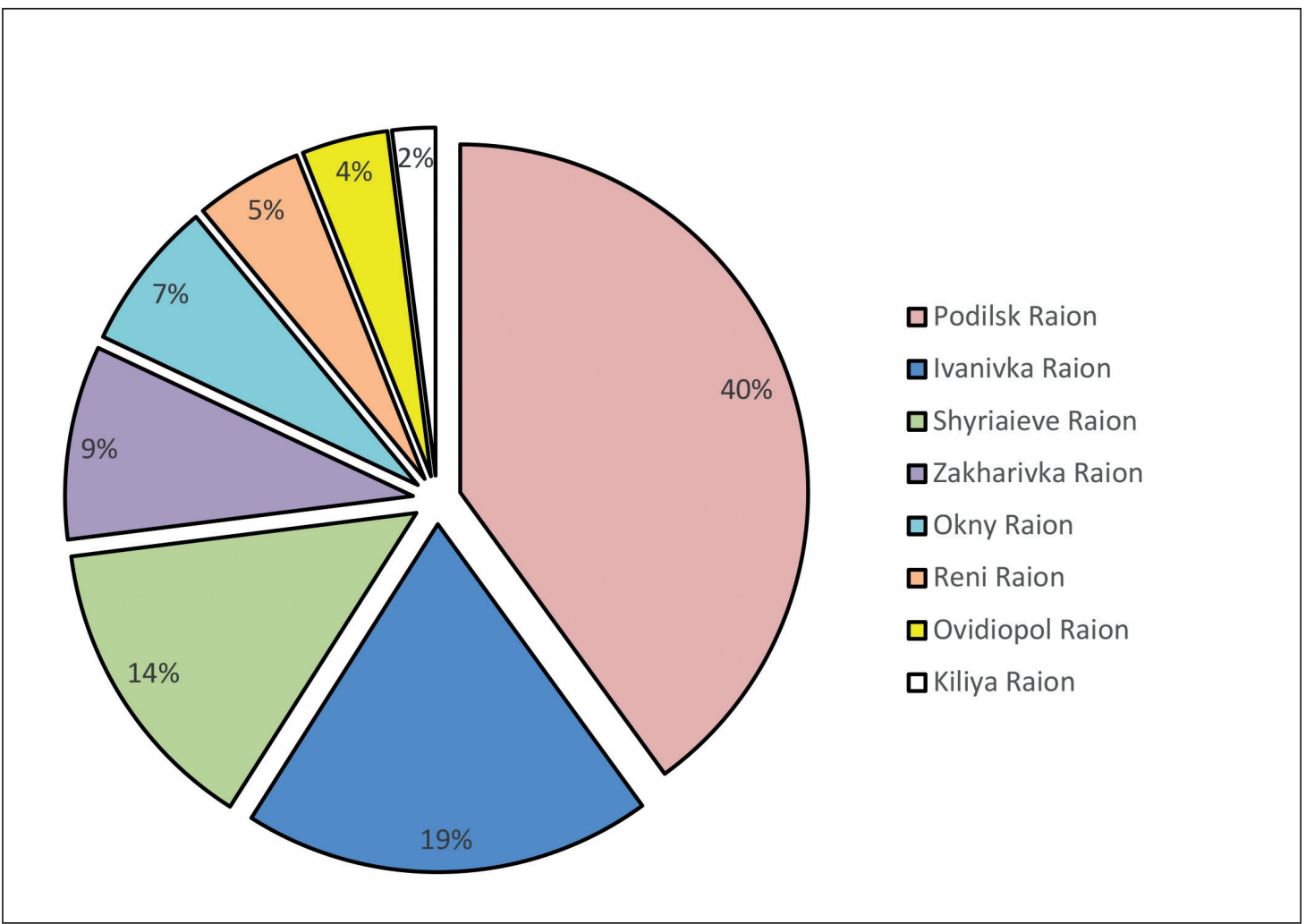

Fig. 5. Distribution of telemedical consultations by raions of Odessa oblast.

hospital of Ovidiopol, the Regional hospital of Velyka Mykhailivka, the Regional hospital of Zakharivka, the Regional hospital of Lybashivka, the Regional hospital of Tarutino, the Regional hospital of Izmail, the Regional hospital of Mykolaivka, the Regional hospital of Teplodar, etc. The regional center of telemedicine is the platform for information and medical events. It includes the following services:

- Medical information system;

- Telemedicine consulting;

- Education;

- Technical maintenance; 

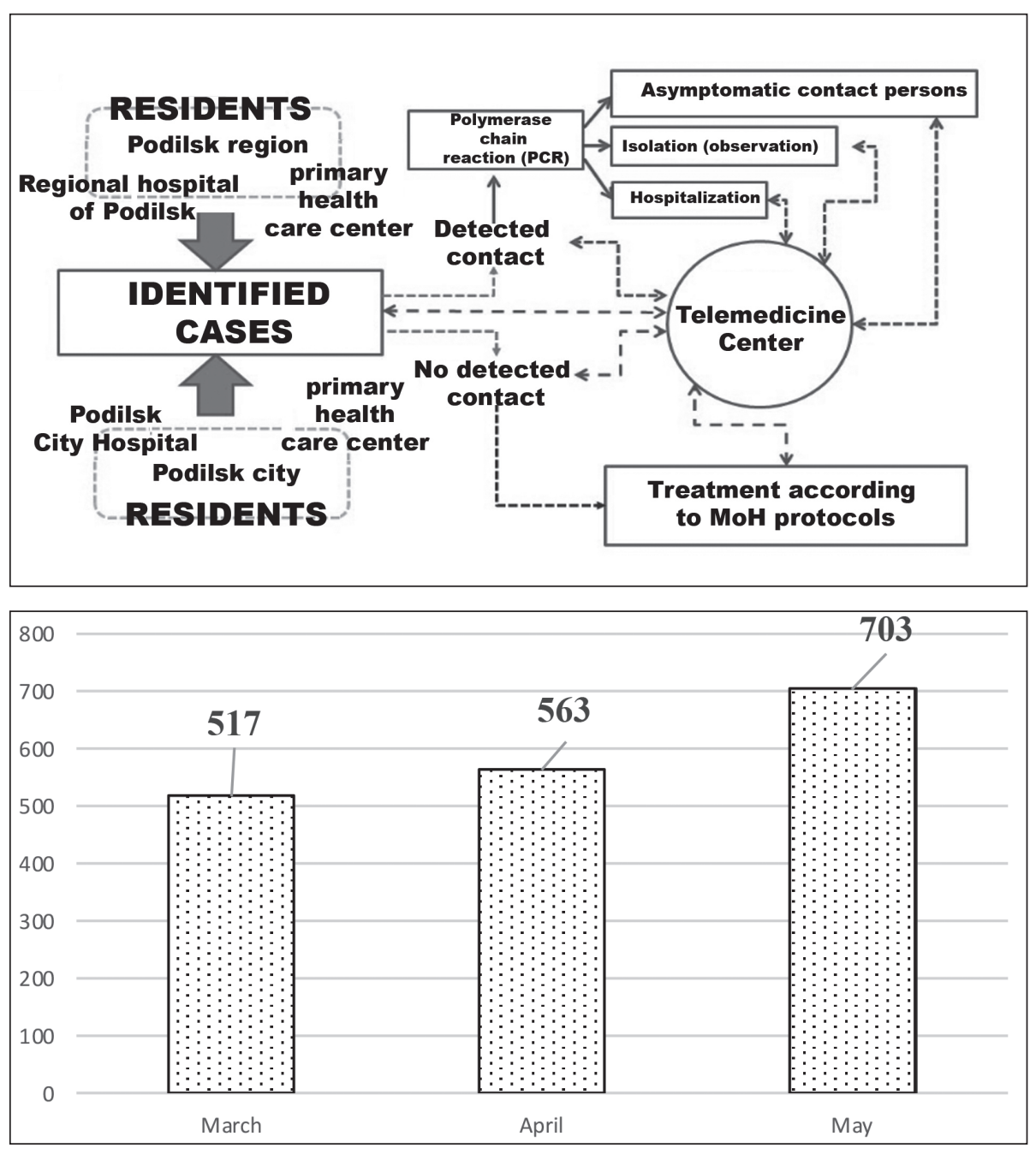

Fig. 6. Algorithm for monitoring the situation in the Podolsk raion

Fig. 7. Telemedicine consultations for non - COVID-19 patients during the quarantine period (March - May)
- Archiving of investigations and laboratory studies results; - Organization of mobile diagnosing teams.

The regional information medical system with a telemedicine domain is located in the cloud-based protected service. This system joins the existing medical tools into a single program interface. The system also includes tools for medical documents turnover, medical documents and consulting video records archiving, as well as the server holding the imaging medical records.

Consulting in urgent cases is the basic function of telemedicine network. In 2019 the system has run 463 urgent consultations; in 290 cases the issues were managed through remote consulting only without a visit of a consulting specialist. In 91 cases outpatient consultations were conducted. In 82 cases patients were transported to healthcare institutions with an escorting anesthesiologist.

At the beginning of COVID-19 epidemics in compliance with the Order No395 of Odessa regional administration "Approval of regional algorithm for coronavirus patients (COVID 19)" the structure of telemedicine network at Odessa regional center of telemedicine has been changed. The network has been re-arranged in order to provide the interactions between all elements of medical care system and to connect other structures, like managing institutions and healthcare institutions running the counter-epidemics actions. The functions of the network include implementation of actions targeting better public access to medical care during the COVID-19 quarantine in Odessa region. The system is design to implement the principle of single medical information space during the COVID-19 quarantine. Provision of common approaches and criteria for healthcare system telemedicine technologies application and evaluation, as well as establishment of possible use and development of telemedicine system during COVID-19 quarantine are also targeted by the system updates.

The algorithm of consultation for patients with suspected coronavirus infection has been outlined (Figure 2).

The new pattern includes the following elements: - Expanded urinalysis

- Standard urinalysis

- Sputum analysis; double sputum analysis

- Chest X-ray - 2 or 3 images

- Chest CT with intravenous contrast (if required)

- Blood analysis (urea and creatinine)

- O2 saturation level

- US examination of pleural cavities

- ECG

Urgent consultations were conducted in patients with suspected coronavirus in compliance with the approved algorithm. 
Medical triage with route establishment is an important element of telemedicine. The template of-telemedicine triage is outlined in Figure 3.

Two types of patients are outlined in the telemedicine triage system: patients with coronavirus infection manifestations and contact persons. These patients are subject to primary telemedicine examination. Symptoms-free patients and patients with mild disease are sent for isolation containment under supervision of the family doctor. The supervising doctor contacts the patient routinely for status monitoring. Mobile medical team can be sent to the patient. These teams are designed to respond the challenges of acute COVID-19.

If high probability of acute COVID-19 is found during the primary remote examination in patients with moderate to severe condition these patients are hospitalized by the specialized emergency ambulance teams to pre-established hospitals designed for appropriate cases.

Telemedicine is also used for training of healthcare professionals. Patterns of patients with suspected coronavirus infection are reviewed during these trainings.

Experts from Healthcare Department, regional and municipal hospitals contributed to trainings that enrolled healthcare institutions management stuff and their subordinates. Patterns of response to COVID-19 cases and patient's route planning are reviewed in compliance with effective normative acts. Special attention is paid to individual protection items use and utilization, possible actions at the suspected infection site, COVID-19 treatment protocols, smear sampling, and resuscitation protocols in COVID-19 patients. Telemedicine training protocols for healthcare institutions seniors and subordinates were developed in compliance with Dreyfus model of skill acquisition.

\section{REVIEW}

During the study period (March 1 - June 1,2020) totally 164 consultations for COVID-19 cases were conducted in 65 patients. 14 healthcare providers were running the consulting.

Note, that the total number of patients with suspected COVID-19 included 18 healthcare professionals and 47 other patients.

During the 3 months' period the number of urgent consultations increased by $13 \%$ compared to similar period prior to quarantine resulting in respective increase in the number of consulting specialists. Specialists in X-ray and pulmonologists experienced the highest burden $(5 \%$ and $16 \%$ respectively).

Table I shows that consultations were most common in patients from 40-65 years' age group with suspected COVID-19 infection.

Also many consultations were reported in patients returning from other countries during the first 14 days prior to infection manifestations (Table II).

Table III lists the reported symptoms.

Figure 4 shows the details regarding remote triage and algorithm of decision making regarding the hospitaliza- tion. Hospitalization was most common in patients with respiratory failure (52 patients). Also patients with no treatment response (34) and rapid disease progression (29) were hospitalized.

The distribution of consultations in various districts of Odessa region was uneven.

Figure 5 shows the highest number of consultations in Podilsk raion due to disease outbreak and the respective decision of the Comission on technogenic and environmental safety and emergencies regarding the enforcement of quarantine measures in the respective area. Note the highest number of healthcare providers with COVID-19 infection reported in Podilsk raion. Therefore, it has been decided to use telemedicine as the basic tool for coordination and consulting of suspected infection cases and for other patients as well.

Use of telemedicine resulted in tailored response to challenges including shifting of patient's routes. The respective case description algorithm has been proposed (Figure 6).

Figure 7 demonstrates higher number of consultations in patients with chronic diseases as well as in complex cases and for palliative reasons. These consultations were justified by patient's safety issues and complex multi-link logistics associated with closure of bus and railway connections in Odessa region during the quarantine. Figure 7 demonstrates the $150 \%$ growth of consultations number.

\section{DISCUSSION}

Experience of other countries points to hospital network overload as the main challenge during COVID-19 epidemics resulting in high level of fatal outcomes both in COVID-19 patients and in other patients with critical conditions who failed to receive timely medical care [12;13]. Many authors report high capacity of telemedicine network as a powerful tool of healthcare institutions coordination in response to COVID-19 patient's overflow [10.11.14]. 5 main directions of telemedicine activities are summarized below:

1. Triage and decisions regarding hospitalization to hospitals designed for COVID-19 patients or to other hospitals.

2. Outpatient consulting in COVID-19 patients who stay at home.

3. Coordination of activities of different hospitals; provision of specialized consulting.

4. Training of healthcare providers for counter-epidemic measures and management of COVID-19 patients.

5. Routine consulting in patients with chronic disease and in palliative cases.

Therefore, organization of telemedicine network in Odessa region is generally compliant with modern trends.

The system of remote consulting in Odessa region was targeted to minimize the time needed for provision of specialized consultations. Most of consultations were focused on analysis of investigations, X-rays, CT imaging, etc.

Application of standardized algorithms enabled minimization of infection transmission both for healthcare providers 
Table III. Classification of patients with COVID-19 according to symptom

\begin{tabular}{ccc}
\hline Symptom & $\begin{array}{c}\text { Patients } \\
\mathbf{n = 6 5}\end{array}$ & $\%$ \\
\hline Cough & 65 & $100 \%$ \\
\hline $\begin{array}{c}\text { Shortness of breath or difficulty } \\
\text { breathing }\end{array}$ & 33 & $50,76 \%$ \\
\hline Respiratory insufficiency & 33 & $50,76 \%$ \\
\hline Chest x-ray findings & 65 & $100 \%$ \\
\hline Vomiting & 6 & $9,23 \%$ \\
\hline Diarrhea & 5 & $7,69 \%$ \\
\hline Nausea & 6 & $9,23 \%$ \\
\hline Abdominal discomfort & 6 & $9,23 \%$ \\
\hline Fever or chills & 28 & $43,07 \%$ \\
\hline Congestion or runny nose & 15 & $23,07 \%$ \\
\hline Sore throat & 49 & $75,38 \%$ \\
\hline New loss of taste or smell & 17 & $26,15 \%$ \\
\hline Headache & 65 & $100 \%$ \\
\hline Muscle or body aches & 53 & $81,43 \%$ \\
\hline Fatigue & 40 & $61,53 \%$ \\
\hline
\end{tabular}

and patients. Use of telemedicine for consulting and triage was crucial during the outbreak in Podilsk city. The clear roadmap has been developed showing possible routes for patients with disease manifestations. The actual hospitalization route depended on groups of reported symptoms.

Remote training of healthcare seniors and providers resulted in beneficial outcomes also. In compliance with Dreifus brothers model, the training levels were Novice and Advanced beginner [15,16]; therefore, high levels of mistakes requiring correction were reported. The trainees were inexperienced enough to fail during dressing in protective clothing. Respectively, trainings were focused on context independent rules and algorithm (if X do Y format). Multiple practical workouts were conducted. The mistakes of trainees were noticed and corrected. After the correction of mistakes, the instructing experts were running the evaluation of trainees.

Telemedicine enabled training of high number of healthcare providers in short terms without a need for experts to travel to training sites. It contributed to lower infection risk and resulted in lower expenses compared to standard trainings in the healthcare network of Odessa region.

Survey results (no statistical analysis conducted) demonstrated high satisfaction with telemedicine system both in COVID-19 patients and in other patients. The results remained promising despite the rapid increase of consultations number and involvement of experts with no prior experience of remote consulting.

However, certain issues are reported in the telemedicine network of Odessa regioni:

First, the low coverage of patients should be noted. The total number of suspected cases was 2210 with 886 infected patients (as of June 1); however, only 65 of them received remote consulting $(7.3 \%)$. However, it cannot be stated that such result was unexpected. This condition is associated with clinical route of medical care designed for COVID-19 patients. Specialized emergency ambulance teams were directed to patients reporting high temperature and signs of respiratory infection. These ambulances were delivering patients to pre-established medical institutions designed for COVID-19 cases.

It's a pity, but ambulance teams were practically neglecting the telemedicine triage system. However, use of this system could have resulted in lower patient's loading of emergency departments.

Family doctors also failed to use the monitoring capacities. In patients reporting disease aggravation family doctors were recommending emergency aid supported by ambulance teams not equipped with telemedicine tools. Inclusion of personal telemedicine tools into the ambulance kits could improve the capacity for consulting in patients who remain at home.

Development of remote consulting scenarios could help to monitor the patients during isolation period: monitoring for patients with symptoms-free disease, specialized consulting for patients with mild disease, medical service for treatment of patients who are unable to reach specialized medical care and even geo-location monitoring for persons who are obliged to remain isolated after having returned from countries with COVID-19 outbreaks.

\section{CONCLUSIONS}

Application of information and communication technologies as the core component has contributed to routing of COVID-19 patients resulting in lower infection level both among patients and healthcare providers.

Involvement of emergency care service to telemedicine triage network in for COVID-19 patients can result in lower burden for emergency departments.

Further development of telemedicine network requires time, resources, specialists and respective normative acts. Application of telemedicine network in Odessa region is an example of successful use of information and communication technologies for public management of healthcare institutions network in response to COVID-19 pandemics. This experience can be shared with other regions of Ukraine.

\section{REFERENCES}

1. World Health Organization (WHO). Pandemic influenza. [Internet]. Geneva:WH0; 2020. [cited 2020 July 01]. Available from: https://www. euro.who.int/en/health-topics/communicable-diseases/influenza/ pandemic-influenza

2. Kyiv School of Economics (KSE) COVID-19: Analysis of the current situation and modeling of disease spread scenarios [Internet]. Kyiv: KSE; 2020 [updated 2020 August 01]. Available from: https://moz. gov.ua/uploads/5/25406-kse_institute_covid_19_moh_kse_ briefing_20200801_vfinfinfin.pdf

3. Online Coronavirus COVID-19 Global Cases [Internet]. Baltimore, MD: Johns Hopkins University, 2020. [cited 2020 July 01]. Available from: http://www.omim.org/ https://gisanddata.maps.arcgis.com/apps/ opsdashboard/index.html\#/bda7594740fd40299423467b48e9ecf6 
4. World Health Organization (WHO). Health workers exposure risk assessment and management in the context of COVID-19 virus [Internet]. Geneva: WH0; 2020. [updated 2020 March 4]. Available from: https://apps.who.int/iris/bitstream/handle/10665/331340/ WH0-2019-nCov-HCW_risk_assessment-2020.1-eng.pdf

5. Peter Kenny. International Council of Nurses (ICN). 90,000 healthcare workers infected with COVID-19 [Internet]. Geneva: ICN; 2020. [updated 2020 May 05]. Available from: https://www.aa.com.tr/en/europe/90000-healthcare-workers-infected-with-covid-19-icn/1831765

6. COVID-19 pandemic in Ukraine Current information about coronavirus and quarantine [Internet]. Kyiv: Cabinet of Ministers of Ukraine; 2020 [cited 2020 July 01]. Available from: https://covid19.gov.ua/en

7. Online Monitoring the situation with the number of hospitalized persons with suspicion and confirmatory cases of kovid-19 in Ukraine [Internet]. Kyiv: The National Health Service of Ukraine (NHSU); 2020 [cited 2020 July 01]. Available from: https://nszu.gov.ua/en/covid/dashboard

8. Vannabouathong C. et al. Novel coronavirus COVID-19: current evidence and evolving strategies //The Journal of bone and joint surgery. American volume. - 2020. - T. 102. - №. 9. - C. 734.

9. NYU Langone Health / NYU School of Medicine. Telemedicine transforms response to COVID-19 pandemic in disease epicenter. [Internet]. ScienceDaily., [updated 2020, April 30]. Available from: www. sciencedaily.com/releases/2020/04/200430150220.htm

10. Ohannessian R., Duong TA., Odone A. Global Telemedicine Implementation and Integration Within Health Systems to Fight the COVID-19 Pandemic: A Call to Action JMIR Public Health Surveill 2020;6(2):e18810 D0I: 10.2196/18810

11. Hollander J. E., Carr B. G. Virtually perfect? Telemedicine for COVID-19. New England Journal of Medicine. 2020. (382). 18.1679-1681.

12. Tao Guo., Yongzhen Fan., Ming Chen., et al Cardiovascular Implications of Fatal Outcomes of Patients With Coronavirus Disease 2019 (COVID-19) JAMA Cardiol. 2020;5(7):811-818. doi:10.1001/jamacardio.2020.1017

13. Kolifarhood G, Aghaali M, Mozafar Saadati H, et al. Epidemiological and Clinical Aspects of COVID-19; a Narrative Review. Arch Acad Emerg Med. 2020;8(1):e41. Published 2020 Apr 1.

14. Portnoy J., Waller M., Elliott T. Telemedicine in the Era of COVID-19. The Journal of Allergy and Clinical Immunology: In Practice. 2020. 8. (5). 1489-1491.
15. Benner, P. Skill Acquisition and Clinical Judgement in Nursing Practice: Towards Expertise and Practical Wisdom. In Practice Wisdom 2019; 225-240.

16. Driver, R., Grose, B., Serafini, M., et al. A focused observation tool using dreyfus stages of skill acquisition as an evaluative scale. West Virginia Medical Journal, 2017; 113(2), 36-42.

ORCID and contributorship:

Dmytro A. Samofalov: 0000-0001-7850-5365 A,B,C,D,F

Nataliya V. Izhytska: 0000-0002-7089-5810 A,B,C,E,F

Natalia M. Dragomyretska: 0000-0001-5713-6724 D, E, F

Artem V. Lyashenko: 0000-0001-5080-6895 ${ }^{B}$

\section{Conflict of interest:}

The Authors declare no conflict of interest.

\section{CORRESPONDING AUTHOR Dmytro A. Samofalov}

Odessa Regional Institute for Public Administration of the National Academy for Public Administration under the President of Ukraine Str. Rope, 83, Offices. 504, 65000, Odesa, Ukraine tel. +380506310186

e-mail:dr.samofalov@gmail.com

Received: 03.08 .2020

Accepted: 28.10 .2020

A - Work concept and design, B - Data collection and analysis, C - Responsibility for statistical analysis, D-Writing the article, $\mathbf{E}$-Critical review, $\mathbf{F}-$ Final approval of the article 